\title{
Attention Deficit Hyperactivity Disorder among Pathological and At-Risk Gamblers Seeking Treatment: A Hidden Disorder
}

\author{
Marie Grall-Bronnec ${ }^{a, b}$ Laura Wainstein ${ }^{a, b}$ Jennyfer Augy ${ }^{a}$ Gaëlle Bouju ${ }^{a}$ \\ Fanny Feuillet $^{b, c}$ Jean-Luc Vénisse ${ }^{a}$ Véronique Sébille-Rivain ${ }^{b, c}$ \\ ${ }^{a}$ Reference Centre for Excessive Gambling, Department of Addictology, ${ }^{b}$ EA 4275 Biostatistics, Clinical Research \\ and Subjective Measures in Health Sciences, and 'Biostatistics Department, University Hospital of Nantes, \\ Nantes, France
}

\section{Key Words}

Pathological gambling $\cdot$ Problem gambling $\cdot$ Attention deficit hyperactivity disorder $\cdot$ Comorbidity $\cdot$ Impulsivity $\cdot$ Urgency

\begin{abstract}
Background: The links between attention deficit hyperactivity disorder (ADHD) and substance use disorders have been the subject of numerous papers. Few studies, however, have focused specifically on the relationship between ADHD and behavioural addictions. The aim of this study was to (i) examine the frequency of pathological and at-risk gamblers having a previous history of ADHD; (ii) give details of the characteristics of this association, and (iii) identify risk factors for a history of ADHD. Methods: 84 pathological and at-risk gamblers were assessed about socio-demographic, gambling and clinical characteristics. Results: Over $25 \%$ of the subjects had a history of ADHD. They were characterized as having more severe gambling problems and a higher level of gambling-related cognitions, a higher frequency of psychiatric comorbidities and an elevated risk of suicide. Finally, they differed in their level and type of impulsivity. Among
\end{abstract}

pathological and at-risk gamblers, a high level of impulsivity, or a history of anxiety disorders, constitute risk factors for a comorbidity with ADHD. Conclusion: The association 'ADHD-problem gambling' therefore appears to be not only frequent, but also linked to factors that are known to worsen the prognosis. Researching this relationship is therefore important to adapt strategies for effective future therapy.

Copyright $\odot 2011$ S. Karger AG, Basel

\section{Introduction}

Attention deficit hyperactivity disorder (ADHD) is a common and debilitating neurodevelopmental disorder [1]. Beginning in childhood, symptoms appear and intensify with age. In $60-85 \%$ of cases the syndrome goes into remission between the ages of 18 and 25. Symptomatic and functional remissions are less common [2]. Hyperactivity and impulsivity tend to decrease, while attention deficit becomes the main symptom of the adult form of ADHD, characterized by emotional and behavioural lability. While ADHD affects between 6 and 9\% of children, its prevalence in adults remains at $4-5 \%[2,3]$. It

\section{KARGER}

Fax +41613061234 E-Mail karger@karger.ch www.karger.com (c) 2011 S. Karger AG, Basel

1022-6877/11/0175-0231\$38.00/0

Accessible online at:

www.karger.com/ear
Marie Grall-Bronnec

Centre de référence sur le jeu excessif

Pavillon Louis Philippe, Hôpital Saint Jacques

85, rue Saint Jacques, FR-44093 Nantes Cedex 1 (France)

Tel. +33 240846 116, E-Mail marie.bronnec@chu-nantes.fr 
seems that $75 \%$ of cases are never diagnosed [3] and only $11 \%$ of sufferers receive suitable treatment [4].

A recent study stated that in subjects suffering from $\mathrm{ADHD}$, the lifetime prevalence of psychiatric comorbidities was around $80 \%$, and that foremost among these were addictive disorders [5]. The links between ADHD and addictions have been the subject of a large number of studies and it is now well established that the existence of ADHD is a major risk factor for initiation into the potentially dangerous consumption of psychoactive substances as well as for the development of substance use disorders (SUD) [6-8].

Prevalence studies are in agreement about the estimate that around $10-25 \%$ of patients seeking treatment for addictions, regardless of the type of addiction, display some kind of hyperactive disorder $[4,5]$. Similarly, in adults with ADHD, the risk of also suffering from a SUD is multiplied by $2-4$, according to the studies [9-11].

Despite this strong association, habitual underdiagnosis of adult ADHD may be even more prevalent among subjects who also suffer from addictive disorders. Indeed, the common symptoms they share could be attributed to the addictive disorder alone, particularly 'impulsivity'.

The underestimation of this comorbidity seems to be even more obvious when the addictive disorder concerned is pathological gambling. As a matter of fact, despite the wealth of literature about the links between addictive disorders and ADHD, there is still very little data about 'pathological gambling-ADHD' comorbidity. Pathological gambling and ADHD share an essential characteristic, 'impulsivity', which suggests a close relationship between the two disorders [12].

The oldest article on this comorbidity dates back almost 25 years [13]. In this study, 14 pathological gamblers and 16 control subjects were assessed retrospectively on the presence of attention deficit disorder in their childhood. The results indicated a strong correlation between pathological gambling and the behaviours linked to attention deficit disorder in childhood. Since then, several studies have confirmed the existence of a link between attention deficit disorder in childhood and later prevalence of pathological gambling [14], or between current attention deficit disorder and pathological gambling [15].

These studies all show a methodological bias. In some cases this is due to a limited sample size (only 14 pathological gamblers were recruited in the Carlton study), or to the retrospective nature of the ADHD assessment, while in others it is a selection bias related to the choice of the population studied. The study by Breyer et al. [16] avoids these pitfalls and is therefore all the more interest- ing. The authors included subjects taken from the general population, aged between 7 and 11 years, and assessed them again between the ages of 18 and 24. Their results indicated that the subjects suffering from ADHD in childhood and continuing on to early adulthood had a greater risk of suffering from gambling problems.

Our study aimed to measure the frequency of ADHD among subjects seeking treatment for problem gambling (PG) in a specialized centre, and evaluate the characteristics of this comorbidity. In particular, we wanted to verify whether the history of ADHD could help to identify a specific profile of pathological and at-risk gamblers, marked by elements of severity (in terms of socio-demographic variability, PG severity, overall psychopathology severity, degree and type of impulsivity). In a previous work (paper submitted for publication), we have shown that the 'urgency' dimension of impulsivity seemed to be the one whose average score came closest to the maximum value and was linked to the severity of pathological gambling. Identification of risk factors for a history of ADHD was also another objective of the study.

\section{Subjects and Methods}

\section{Sample}

Since September 2008, an exhaustive clinical assessment was carried out systematically on all patients who were starting to be treated for PG in our department (Addictions Care Centre, University Hospital of Nantes, France) prior to the first medical consultation. The objective of this assessment is primarily to assist the psychiatrist with a comprehensive collection of information. Moreover, each subject was asked whether data about them could be used, anonymously, for the sake of research.

This study was conducted with a sample group of consecutive problem gamblers seeking treatment, between April 2009 and September 2010. The main criterion for inclusion was being an 'at-risk gambler' or a 'pathological gambler'. Exclusion criteria included cognitive impairment and difficulties in reading and writing French.

All participants underwent a structured interview and completed self-report questionnaires (see below). To shorten the duration of the assessment at the centre, the patients received the questionnaires beforehand by post and they were asked to complete them at home. If the questionnaires were not completed on the day of the evaluation, the subjects were asked to complete them on the spot immediately. Finally, if they refused, they were asked to complete them at home, and give them to the psychiatrist at the first medical appointment.

Despite several attempts, we were not able to obtain all the completed self-questionnaires for all the subjects.

This study was approved by the local research ethics committee, and all subjects provided written informed consent (no patients refused to give consent). 


\section{Measurements}

We have chosen the following assessment tools because of their clinical interest on the one hand, their widespread use in many research on the other hand, their validation in French at last. We favoured the use of self-report tools whenever possible, to reduce the duration of the clinical assessment and to promote the acceptance of patients.

\section{Clinical Characteristics}

Wender-Utah Rating Scale-Child (WURS-C) $[17,18]$. This selfreport questionnaire is a tool that has been validated for retrospective evaluation in the adult of ADHD in childhood. Its specificity $(89.1 \%)$ is good, which limits the risk of giving wrong diagnosis. It is designed to assess ADHD symptoms represented by 25 items on 5-point Likert scales. The authors thought that a score $\geq 46 / 100$ would allow for the diagnosis to be made.

Adult ADHD Self-Report Scale (ASRS-v1.1) [19, 20]. This selfreport scale of adult ADHD is based on the 18 diagnostic criteria of the DSM-IV-TR [21], scored according to their frequency. We used the ASRS screener, which consists of 6 out of these 18 questions that were selected based on stepwise logistic regression to optimize concordance with the clinical classification [19]. According to the ASRS-v1.1 Symptom Checklist instructions, if four or more marks appear in the darkly shaded boxes within Part A, then the patient has symptoms highly consistent with ADHD. Some authors concluded that the ASRS-v1.1 screener was a simple screening tool that was useful and had acceptable validity for the identification of ADHD among addicted patients [22]. In particular, the sensitivity $(87.5 \%)$ and negative predictive value $(95.7 \%)$ are good, what is expected of a screening tool. Based on the results of the WURS-C v1.1 and the ASRS screener, it is possible to classify subjects into three groups: 'No history of ADHD' (WURS score $<46$ ), 'ADHD only in childhood' (WURS score $\geq 46$ and three or less marks in the darkly shaded boxes within Part A of the ASRS-v1.1), 'ADHD probably persistent at adulthood' (WURS score $\geq 46$ and four or more marks in the darkly shaded boxes within Part A of the ASRS-v1.1).

Mini International Neuropsychiatric Interview (MINI) [23]. The fifth version of this structured diagnostic interview allows for the main axis-I psychiatric disorders (and the antisocial personality disorder) of the DSM-IV to be explored in a quick and standardized way.

UPPS Impulsive Behaviour Scale (UPPS) [24, 25]. This is a 45item self-questionnaire developed by Whiteside et al. [24], with the aim of measuring four distinct pathways to impulsive behaviour: 'Urgency' (tendency to engage in impulsive behaviours under conditions of negative affects), (lack of) 'Premeditation' (difficulty in thinking and reflecting on the consequences of an act before engaging in that act), (lack of) 'Perseverance' (individual's inability to remain focused on a task that may be boring or difficult) and 'Sensation-Seeking' (tendency to enjoy and pursue activities that are exciting and openness to trying new experiences that may or may not be dangerous). We preferred to use that instrument rather than another to measure the impulsivity, because of the dimensions explored and their links with hypothetical motivational and executive processes (difficulty in inhibiting prepotent responses for the 'Urgency' facet, non-optimal decisionmaking for the 'Premeditation' facet, difficulty in inhibiting intrusive thoughts and memories for the 'Perseverance' facet and hypersensitivity to positive reinforcement for the 'SensationSeeking' facet) [26]. In another work (paper in revision for publication), we showed that there were several clinical profiles as a function of degree and type of impulsivity, assessed by the UPPS, in pathological gamblers.

\section{Gambling Characteristics}

Pathological Gambling Section in the DSM-IV [27]. We used the mini screening test for pathological gambling, based on the 10 diagnostic criteria of the DSM-IV, firstly in a categorical approach in order to include participants in the study, and to obtain three categories of problem gamblers: 'at-risk gamblers' (showing 3 or 4 criteria), 'pathological gamblers' (showing 5-7 criteria) and 'severe pathological gamblers' (showing $8-10$ criteria). Secondly, we added the positive DSM-IV criteria to get a severity score, in a dimensional approach.

Gambling Attitudes and Beliefs Survey (GABS) [28]. The GABS is a self-rated questionnaire constructed to measure cognitive biases, irrational beliefs, positively valued attitudes to gambling, subjective arousal and gambling behaviours (including withinsession chasing). It is composed of 35 items. Respondents are asked to use a 4-point Likert scale to indicate the extent to which they agree with each statement. A high overall score on the GABS indicates a high level of irrational beliefs and attitudes about gambling (mean GABS scores in non-problem gamblers $=76.07$ vs. mean GABS scores in problem gamblers and pathological gamblers seeking treatment is 92.11 and 92.65 , respectively). We used the GABS because we have validated it in French (paper submitted for publication). The French version showed good psychometric properties.

Other Gambling Characteristics. In the structured interview, we were able to identify the favourite type of game for each subject. Lottery games, slot machines, scratch cards, etc. were thus classified under 'pure chance games', sports or horse-racing bets as well as black jack under 'chance games with pseudo-skills', and finally, poker (including Texas Hold'em poker) under 'chance games with elements of skills', according to the classification proposed by Boutin [29]. This interview also allowed us to define the medium or outlet habitually used for gambling (on- or off-line) and the main stages of the progression of the gambling habit.

\section{Statistical Analysis}

A descriptive analysis of the socio-demographic, clinical and gambling characteristics was carried out. Exploratory univariate analyses were performed in the following way. The links between the socio-demographic, clinical and gambling characteristics on the one hand, and the existence or absence of a history of ADHD on the other hand, were studied using Student tests for the quantitative variables and $\chi^{2}$ or Fisher tests for the qualitative variables.

Thereafter, multivariate analyses were performed using an iterative selection procedure to select the variables that were significantly associated with ADHD, as assessed by the likelihood ratio test (variable candidates for the model were those associated with ADHD in univariate analyses with the $p<0.20$ criterion and subsequently selected in the model using the $p<0.05$ criterion). The corresponding odds ratio and associated $95 \%$ confidence interval were estimated. Discrimination of the final logistic model which describes its ability to discriminate between the presence and absence of a history of ADHD was assessed using the area 
Table 1. Socio-demographic and gambling characteristics of the total sample

\begin{tabular}{ll}
\hline & $\begin{array}{l}\text { Mean (SD) or } \\
\text { percentage }\end{array}$ \\
\hline $\begin{array}{l}\text { Socio-demographic characteristics ( } n=84) \\
\text { Male }\end{array}$ & $85.7 \%$ \\
Age, years & $41.8 \pm 13.5$ \\
High-school graduates & $53.6 \%$ \\
\hline Gambling characteristics ( $n=84$ or $n=73)$ & \\
Severity of gambling (categorical approach) & \\
$\quad$ 'At-risk gamblers' & $15.5 \%$ \\
$\quad$ 'Pathological gamblers' & $47.6 \%$ \\
$\quad$ 'Severe pathological gamblers' & $36.9 \%$ \\
Severity of gambling (dimensional approach) & \\
$\quad$ DSM-IV score & $6.6 / 10 \pm 1.9$ \\
Severity of gambling-related cognitions (n = 73) & \\
$\quad$ GABS score & $90.2 \pm 13.7$ \\
Favorite type of game & \\
$\quad$ 'Pure chance games' & $40.5 \%$ \\
$\quad$ 'Chance games with pseudo-skills' & $44 \%$ \\
$\quad$ 'Chance games with elements of skills' & $15.5 \%$ \\
Usual medium of game & $70.2 \%$ \\
$\quad$ Off-line & $29.8 \%$ \\
$\quad$ On-line & \\
\hline
\end{tabular}

under the receiver operating characteristic (ROC) curve and the goodness-of-fit of the model was assessed using the Hosmer-Lemeshow test. The statistical analysis was carried out with SAS 9.1 and $\mathrm{R}$ statistical software (SAS Institute, Inc.).

The conditions for validity were verified for all of the tests and the models.

\section{Results}

\section{Description of the Sample Group}

Socio-Demographic Characteristics. A total of 84 subjects, aged 19-74 years, took part in this study. The sex ratio is clearly in favour of men, and the majority of the sample were high-school graduates. The data relating to socio-demographic characteristics are presented in table 1 .

Gambling Characteristics. As shown in table 1, the patients were mostly categorized as 'pathological gamblers', with a mean DSM-IV score of 6.6/10. The level of gambling-related cognitions was relatively high. Most patients were 'off-line' gamblers, with a preference for the 'chance games with pseudo-skills'.
Table 2. Disorders associated with gambling problems in the total sample: ADHD in childhood diagnosed retrospectively using the WURS-C; ADHD persistent in adulthood screened using the ASRS v1.1 screener; other psychiatric and addictive disorders diagnosed by MINI

\begin{tabular}{lr}
\hline & $\begin{array}{l}\text { Fre- } \\
\text { quency }\end{array}$ \\
\hline No history of ADHD $(\mathrm{n}=76)$ & $73.7 \%$ \\
History of ADHD $(\mathrm{n}=76)$ & $26.3 \%$ \\
$\quad$ ADHD only in childhood & $15.8 \%$ \\
$\quad$ ADHD probably persistent at adulthood & $10.5 \%$ \\
Mood disorders, current or past $(\mathrm{n}=82)$ & $42.7 \%$ \\
Risk of suicide $(\mathrm{n}=82)$ & $39.0 \%$ \\
Anxiety disorders, current or past $(\mathrm{n}=82)$ & $32.9 \%$ \\
Tobacco dependence, current or past $(\mathrm{n}=82)$ & $52.4 \%$ \\
Alcohol use disorders, current or past $(\mathrm{n}=82)$ & $41.5 \%$ \\
Other substance use disorders, current or past $(\mathrm{n}=82)$ & $29.3 \%$ \\
Antisocial personality disorder $(\mathrm{n}=81)$ & $4.9 \%$
\end{tabular}

Clinical Characteristics. As the results displayed in table 2 indicate, psychiatric disorders associated with PG were common. In particular, $26.3 \%$ of subjects have a history of childhood ADHD (15.8\% of the sample displayed characteristics of ADHD only in childhood, and $10.5 \%$ displayed characteristics of ADHD probably persisting into adulthood). The type and level of 'impulsivity' were evaluated using the UPPS and the average scores were $34.6 / 48$ ( $\mathrm{SD}=6.4$ ) for the 'urgency' facet, $24.5 / 44(\mathrm{SD}=4.9)$ for the 'lack of premeditation' facet, $21.1 / 40(\mathrm{SD}=3.8)$ for the 'lack of perseverance' facet and $27.9 / 48(\mathrm{SD}=7.8)$ for the 'sensation-seeking' facet $(\mathrm{n}=$ 74). Although there was no link between the average score for each of the 4 facets and the subjects' gender, age was negatively correlated with lack of perseverance $(\mathrm{p}<$ $0.05)$.

\section{Comparison of 'No History of ADHD' and 'History of} ADHD' Subgroups according to Socio-Demographic,

Clinical and Gambling Characteristics

On account of the low number of subjects in the subgroups 'ADHD only in childhood' $(\mathrm{n}=12)$ and 'ADHD probably persistent at adulthood' $(\mathrm{n}=8)$, subjects were combined together into a single group of subjects considered as having a 'History of ADHD' $(\mathrm{n}=20)$.

The univariate analysis showed that more than half of the variables were associated with the history of ADHD at the 0.20 level of significance (table 3 ).

After multivariate analysis, only two variables remained independently associated with ADHD, namely 
Table 3. Comparison of 'No history of ADHD' and 'History of ADHD' groups, according to socio-demographic, gambling and clinical variables

Mean (SD) or percentage

\begin{tabular}{lll}
\hline No history of & 'History of & p value \\
ADHD' $(n=56)$ & ADHD' $(n=20)$ &
\end{tabular}

Socio-demographic characteristics $(n=76)$

Male

Age, years

$82.1 \%$

$42.2 \pm 13.6$

$90 \%$

0.499

High-school graduates

$60.7 \%$

$43.3 \pm 12.3$

0.751

Gambling characteristics $(n=76)$

Severity of gambling (categorical approach)

'At-risk gamblers'

'Pathological gamblers'

'Severe pathological gamblers'

Severity of gambling (dimensional approach)

DSM-IV score

Severity of gambling-related cognitions $(n=73)$

GABS score

Favorite type of game

'Pure chance games'

'Chance games with pseudo-skills'

'Chance games with elements of skills'

Usual medium of game

Off-line

On-line

Gambling history

Age at initiation to gambling

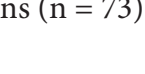

Psychiatric and addictive comorbidities (MINI) $(n=74)$

Mood disorders, current or past

Risk of suicide

Anxiety disorders, current or past

Tobacco dependence, current or past

Alcohol use disorders, current or past

Other substance use disorders, current or past

Antisocial personality disorder

Impulsivity (UPPS) $(n=74)$
Urgency
Lack of premeditation
Lack of perseverance
Sensation seeking

Impulsivity (UPPS) $(n=74)$

Urgency

Lack of perseverance

$24.4 \pm 4.3$

$20.6 \pm 3.4$

$27.0 \pm 7.9$

$\begin{array}{ll}16.1 \% & 10 \% \\ 53.6 \% & 35 \% \\ 30.3 \% & 55 \%\end{array}$

0.164

$35 \%$

$55 \%$

$\begin{array}{lll}6.4 \pm 1.7 & 7.4 \pm 2.0 & 0.041\end{array}$

$\begin{array}{lll}87.2 \pm 11.5 & 98.7 \pm 16.3 & 0.001\end{array}$

$\begin{array}{lll}37.5 \% & 55 \% & 0.013\end{array}$

$50 \% \quad 15 \%$

$12.5 \% \quad 30 \%$

$\begin{array}{lll}64.3 \% & 80 \% & 0.194\end{array}$

$35.7 \% \quad 20 \%$

$\begin{array}{lll}19.2 \pm 10.6 & 20.6 \pm 8.3 & 0.616\end{array}$

$\begin{array}{lll}35.0 \pm 13.3 & 36.3 \pm 12.8 & 0.724\end{array}$

$\begin{array}{ccc}34.5 \% & 63.2 \% & 0.029 \\ 34.5 \% & 62.5 \% & 0.029 \\ 23.6 \% & 57.9 \% & 0.005 \\ 45.5 \% & 68.4 \% & 0.084 \\ 37.6 \% & 63.2 \% & 0.042 \\ 29.1 \% & 31.6 \% & 0.838 \\ 0 \% & 15.8 \% & 0.014\end{array}$

anxiety disorders (current or past) and urgency, both being identified as risk factors for a history of ADHD among pathological and at-risk gamblers (table 4). The HosmerLemeshow goodness-of-fit test showed that the final model was well calibrated with $\mathrm{p}=0.874$ (a large $\mathrm{p}$ value indicating a good model fit). The area under the ROC curve was 0.82 , showing that the model discriminated well between patients who had a history of ADHD and those who did not.

Table 4. Multivariate logistic regression analysis (final model) showing factors associated with a 'History of ADHD' $(n=72)$

\begin{tabular}{llll}
\hline Variables & OR & $\mathrm{IC}_{95 \%}(\mathrm{OR})$ & $\mathrm{p}$ value \\
\hline Anxiety disorders, current or past & 4.08 & {$[1.51 ; 14.48]$} & 0.0294 \\
Urgency & 1.20 & {$[1.07 ; 1.35]$} & 0.0016
\end{tabular}

OR = Odds Ratio $; \mathrm{IC}_{95 \%}=95 \%$ confidence interval. 


\section{Discussion}

This cross-sectional study found a high rate of ADHD history among a sample of pathological and at-risk gamblers seeking treatment. Our results therefore fell within the range of values found among populations of subjects seeking treatment for addictions, in particular for SUD $[4,5,8]$. Some authors concluded that the association 'ADHD addiction' is characterized by a greater addiction severity and more comorbid psychopathology $[5,8]$. It is clear that pathological gambling and SUD have something else in common, thus supporting the concept of including pathological gambling in the nosographic framework of addictions, as provided for in the DSM-V.

Besides confirming that ADHD is a disorder that is frequently associated with pathological gambling, our work was one of the rare studies that researched this association in a sample group of pathological and at-risk gamblers. It is therefore of particular interest to clinicians dealing with this type of addiction, and should encourage them to look into the presence of ADHD in childhood and verify whether it persisted in adult life. This research must be carried out with great care since our study indicated that ADHD-PG comorbidity seems to be associated with a particular profile, marked by its severity at various levels.

Firstly, we found that the subjects with a history of ADHD had a lower level of education. Many control studies, in which the subjects were matched on IQ, arrived at the conclusion that the existence of ADHD led to difficulties at school (learning difficulties, repeating a grade or grades, leaving school at an early age) [30-32].

Secondly, the subjects with a history of ADHD appeared to have a higher severity of PG and a higher level of cognitive distortions specific to gambling. Gamblingrelated cognitions are directly linked to the severity of the gambling problem [28] and reflect the failure to understand or take into account the random and uncontrollable nature of chance [33]. They contribute to the persistence of PG.

For many authors, ADHD and PG may share several neurocognitive anomalies, such as impulsivity, lack of inhibition, attention deficit, changes in executive functions, decision-making difficulties, and even disruptions to the processes of reward and punishment $[14,16,34,35]$. Impulsivity is considered to be a cardinal feature for both ADHD and PB. It is a complex, multidimensional concept. We have previously noted that impulsivity could be described according to 4 dimensions ('Urgency', (lack of) 'Premeditation', (lack of) 'Perseverance' and 'Sensation- seeking'). Other authors identify 3 core domains: 'Inhibition of pre-potent responses', 'Delay impulsivity' and 'Reflection impulsivity', which refers to impulsivity at the pre-decisional stage [36]. Pathological gamblers show neuropsychological impairments in 'Reflection impulsivity' and 'Risky decision-making', as witnessed by deficits in tasks linked to ventromedial prefrontal cortical dysfunction (the same abnormalities are found in patients with alcohol dependence) [37]. The authors suggested that these impairments could reflect pre-existing vulnerability factors in the addictions. On 'Reflection impulsivity' task, pathological gamblers have a higher rate of errors than healthy controls, but are not different in terms of response time [38]. Little is known about 'Reflection impulsivity' in adult ADHD. The results of a study carried out in children with ADHD showed that they made more poor decisions than healthy controls, but they did not differ in terms of the amount of information they sampled, the degree of uncertainty tolerated prior to making a decision, or the speed at which they made their final choice [36]. It can be assumed that PG and ADHD are perhaps underpinned by the same form of impulsivity. The poor quality of decision-making may be linked to the subjects' inability to use the available information in their advantage [36].

The anomalies previously quoted result in a series of incorrect decision-making, in this case, repeated gambling, despite the long-term damages. Whereas nonproblem gamblers tend to decrease their degree of confidence in their gambling-related cognitions over the course of a gambling session and then stop gambling, the opposite is true for pathological gamblers. They continue to gamble because they are convinced that they will win. This shows evidence of their diminished cognitive flexibility [34]. Gambling-related cognitions would also be mediated by brain networks involving ventromedial prefrontal cortex [39]. One might logically presume that when ADHD and PG are both present, the neurocognitive anomalies would be greater than when these disorders are observed separately. This may, in part, explain the difference in GABS scores between the two groups. Subjects demonstrating the ADHD-PG combination seem to prefer pure chance games (notably slot machines in casinos or scratch cards). These are games that do not require total attention.

Thirdly, our study found that ADHD-PG comorbidity tends to be more frequently associated with other psychiatric or addictive comorbidities. These associations are often noted in case of ADHD [4, 40, 41] and PG [42-48]. One might also evoke cumulative risk factors. In our 
sample of pathological and at-risk gamblers, anxiety disorders (current or past) represent a risk factor for having a history of ADHD in itself. The links between ADHD and anxiety disorders have been raised in many studies $[10,11]$, and some authors even included anxiety among the diagnostic criteria for ADHD [49]. It is important to note that the risk of suicide was greater among problem gamblers with a history of ADHD and that this group also had a higher impulsivity level for the 'urgency' dimension. This shows that ADHD-PG comorbidity should be taken seriously in clinical evaluations. Blaszczynski et al. [50] described a subgroup of pathological gamblers characterized by the severity of their impulsivity, which they called 'antisocial impulsivist'. Besides the high level of impulsivity and the history of comorbidities characterized by this dimension (ADHD, SUD and antisocial behaviour), this subtype of problem gamblers suffered from behavioural, emotional and cognitive vulnerabilities [51]. In our study, the subjects with the combination of ADHD and PG seemed to match the subgroup 'antisocial impulsivist problem gamblers'. However, we were surprised to find that the subjects of our group with a history of ADHD did not start to gamble at a younger age. Early gambling constitutes one of the characteristics of the subgroup 'antisocial impulsivist problem gamblers'. One explanation could be the bias of failing memory since subjects were invited to remember and retrace the stages of their gambling habit as part of the assessment procedure.

Finally, we focused our study on impulsivity. The common point between ADHD and PG is, in all likelihood, this personality trait. The two nosographic items effectively make impulsivity a key symptom. Recently, several studies confirmed that the 'urgency' facet of impulsivity played a crucial role in the emergence of problem or maladaptive behaviours such as pathological gambling, compulsive buying and problem use of mobile phones and the internet $[52,53]$. The results of our study go beyond this, demonstrating that it is this dimension of urgency that best allows us to differentiate between pathological and at-risk gamblers with or without a history of ADHD. A high score of 'urgency' constitutes a risk factor for having a history of ADHD. As Cyders and Smith [54] put it, 'positive and negative urgency are personality traits that represent individual differences in the tendency to engage in ill-considered, rash action when experiencing intense emotion'. It is widely recognized that for many of the subjects suffering from ADHD, the consumption of psychoactive substances represents an attempt to selfmedicate (noting, for example, the attention-promoting effect of tobacco, the sedative effect of alcohol and the stimulating effect of cocaine). The same process can be seen in gambling. Characterized by a particularly high level of urgency, overcome by their emotions and not knowing how to deal with them, these subjects seem to adopt an adaptation strategy which is effective in the short term, but which interferes with their self-control abilities, ultimately leading to wrong decision-making (getting involved in gambling) and then bringing negative consequences in the long run [52].

These results must be viewed in the context of several limitations. Firstly, this is a cross-sectional study. Supporting causal links between various events is therefore very difficult. Thus, we cannot say whether the presence of ADHD in childhood is responsible for the higher level of urgency, or whether a higher level of urgency, as a characteristic of temperament, is a risk factor for the incidence of ADHD. At any rate, the emergence of gambling problems in later life appears to be related to both the level of urgency and the history of ADHD, and a high level of urgency is identified as a risk factor for having history of ADHD among our patients with PG.

The sample's representativity to other populations is difficult to estimate, and the frequency estimate may reflect only our clinic. The sample size is also relatively small. Thus, the precision of the estimate and the ability to compare it with other clinical samples are limited. But it was however enough to highlight many interesting differences between the 'History of ADHD' and 'No history of ADHD' subgroups. Finally, the sample size also reflects the difficulty to recruit pathological gamblers seeking treatment. It is assumed that only $3-11 \%$ of them have access to care [55]. In any case, there is little available literature with a sample of 84 pathological and at-risk gamblers seeking treatment.

One might also criticize the retrospective nature of the ADHD assessment in childhood. Memory failure and biases can lead to false positives as well as false negatives. Also, diagnosis of ADHD in adulthood is merely suspected, in so far as the ASRS-v1.1 screener is only a screening tool and not a diagnostic tool. However, we took the precautions to only include in our group subjects who probably did have ADHD in childhood (according to the diagnostic criteria of the DSM-IV) and who still had characteristic symptoms in adulthood. For future investigations, we will be careful to use an instrument to assert with more certainty the diagnosis of ADHD, such as physician-administered Adult ADHD Clinical Diagnostic Scale (ACDS) [56] or the structured Diagnostic Interview for Adult ADHD (DIVA) [57]. 
In addition, current and past comorbidities were treated in an identical manner. It would probably be interesting to differentiate them.

Finally, we lacked certain elements of data, mostly regarding the self-report questionnaires. The reason for this would be the procedure for data collection.

In addition to gaining a better understanding of the psychological and neurobiological mechanisms that underlie pathological gambling with respect to the associated characteristics, the most important result of this work is to be able to focus on determining the best strategies for therapy. This raises the question of prescribing specifically listed medication in the treatment of ADHD (primarily methylphenidate or atomoxetine). To date, there is no data available about the benefits of these treatments for patients with ADHD and PG. Methylphenidate, prescribed for patients with ADHD and bulimia nervosa (another form of behavioural addiction) has, in some cases, brought improvement in eating disorder symptoms as well as ADHD symptoms (for a review, see Nazar et al. [58]). Psychostimulants could, indeed, reduce the overall level of impulsivity.

Moreover, specific psychotherapy interventions should be offered. Blaszczynski and Nower [51] advise offering intensive and prolonged cognitive-behavioural type interventions, particularly to 'antisocial impulsivist problem gamblers' in order to control impulsivity. Finally, Cyders and Smith [54] suggest helping subjects with a high level of urgency to 'control' their distress, due to intense emotional states, and not use immediate behavioural reactions as an escape.
Another way is the primary prevention of PG, with the treatment of ADHD in children. A study has shown that intervention-induced reductions in ADHD symptoms at age 9 may protect children from early-onset smoking [59].

In conclusion, $\mathrm{ADHD}$, whether it has improved since childhood or whether it is still persistent in adulthood, is relatively frequent among pathological and at-risk gamblers seeking treatment in a specialized centre. This comorbidity is associated with elements of severity of varying degrees, and it can be assumed that these harm the prognosis. Risk factors for having also a history of ADHD are identified. The promising results of this study encourage us to pursue our efforts in this direction by increasing the sample size in order to compare subjects according to whether ADHD persists into adulthood or not, and to further investigate the most interesting associations in confirmatory analyses.

It would be particularly relevant to add to our clinical assessment tasks to better specify the neurocognitive impairments specifically linked to each subgroup.

\section{Disclosure Statement}

The Reference Centre for Excessive Gambling has received funding directly from the University Hospital of Nantes and gambling industry operators (FDJ and PMU). Scientific independence towards gambling industry operators is warranted. There were no constraints on publishing.

\section{References}

1 Halperin JM, Trampush JW, Miller CJ, Marks DJ, Newcorn JH: Neuropsychological outcome in adolescents/young adults with childhood ADHD: profiles of persisters, remitters and controls. J Child Psychol Psychiatry 2008;49:958-966.

- 2 Wong IC, Asherson P, Bilbow A, Clifford S, Coghill D, DeSoysa R, Hollis C, McCarthy S, Murray M, Planner C, Potts L, Sayal K, Taylor E: Cessation of attention deficit hyperactivity disorder drugs in the young (CADDY) - a pharmacoepidemiological and qualitative study. Health Technol Assess 2009; 13:iii-iv, ix-xi, 1-120.

3 Goodman DW, Thase ME: Recognizing ADHD in adults with comorbid mood disorders: implications for identification and management. Postgrad Med 2009;121:2030.
4 Barkley RA, Brown TE: Unrecognized attention-deficit/hyperactivity disorder in adults presenting with other psychiatric disorders. CNS Spectr 2008;13:977-984.

- 5 Adler LA, Guida F, Irons S, Rotrosen J, O'Donnell K: Screening and imputed prevalence of $\mathrm{ADHD}$ in adult patients with comorbid substance use disorder at a residential treatment facility. Postgrad Med 2009;121: 7-10.

-6 Barkley RA, Fischer M, Smallish L, Fletcher $\mathrm{K}$ : Young adult follow-up of hyperactive children: antisocial activities and drug use. J Child Psychol Psychiatry 2004;45:195-211.
7 Biederman J, Wilens T, Mick E, Faraone SV, Weber W, Curtis S, Thornell A, Pfister K, Jetton JG, Soriano J: Is ADHD a risk factor for psychoactive substance use disorders? Findings from a four-year prospective follow-up study. J Am Acad Child Adolesc Psychiatry 1997:36:21-29.

-8 Carpentier PJ, van Gogh MT, Knapen LJ, Buitelaar JK, De Jong CA: Influence of attention deficit hyperactivity disorder and conduct disorder on opioid dependence severity and psychiatric comorbidity in chronic methadone-maintained patients. Eur Addict Res 2011;17:10-20.

-9 Brod M, Johnston J, Able S, Swindle R: Validation of the adult attention-deficit/ hyperactivity disorder quality-of-life scale (AAQoL): a disease-specific quality-of-life measure. Qual Life Res 2006;15:117-129. 
10 Kessler RC, Adler L, Barkley R, Biederman J, Conners CK, Demler O, Faraone SV, Greenhill LL, Howes MJ, Secnik K, Spencer T, Ustun TB, Walters EE, Zaslavsky AM: The prevalence and correlates of adult ADHD in the United States: results from the National Comorbidity Survey Replication. Am J Psychiatry 2006;163:716-723.

- 11 Fayyad J, De Graaf R, Kessler R, Alonso J, Angermeyer M, Demyttenaere K, De Girolamo G, Haro JM, Karam EG, Lara C, Lepine JP, Ormel J, Posada-Villa J, Zaslavsky AM, Jin R: Cross-national prevalence and correlates of adult attention-deficit hyperactivity disorder. Br J Psychiatry 2007;190:402-409.

-12 Derevensky JL, Pratt LM, Hardoon KK, Gupta R: Gambling problems and features of attention deficit hyperactivity disorder among children and adolescents. J Addict Med 2007;1:165-172.

-13 Carlton PL, Manowitz P, McBride H, Nora R, Swartzburg M, Goldstein L: Attention deficit disorder and pathological gambling. J Clin Psychiatry 1987;48:487-488.

-14 Rugle L, Melamed L: Neuropsychological assessment of attention problems in pathological gamblers. J Nerv Ment Dis 1993;181:107112.

-15 Specker SM, Carlson GA, Christenson GA, Marcotte M: Impulse control disorders and attention deficit disorder in pathological gamblers. Ann Clin Psychiatry 1995;7:175179.

16 Breyer JL, Botzet AM, Winters KC, Stinchfield RD, August G, Realmuto G: Young adult gambling behaviors and their relationship with the persistence of ADHD. J Gambl Stud 2009;25:227-238.

17 Ward MF, Wender PH, Reimherr FW: The Wender-Utah Rating Scale: an aid in the retrospective diagnosis of childhood attention deficit hyperactivity disorder. Am J Psychiatry 1993;150:885-890.

18 Caci HM, Bouchez J, Bayle FJ: An aid for diagnosing attention-deficit/hyperactivity disorder at adulthood: psychometric properties of the French versions of two WenderUtah Rating Scales (WURS-25 and WURSK). Compr Psychiatry 2010;51:325-331.

$\checkmark 19$ Kessler RC, Adler L, Ames M, Demler O, Faraone S, Hiripi E, Howes MJ, Jin R, Secnik K, Spencer T, Ustun TB, Walters EE: The World Health Organization Adult ADHD Self-Report Scale (ASRS): a short screening scale for use in the general population. Psychol Med 2005;35:245-256.

-20 Caci H, Bouchez J, Bayle FJ: Inattentive symptoms of ADHD are related to evening orientation. J Atten Disord 2009;13:36-41.

21 APA: Diagnostic and Statistical Manual of Mental Disorders, ed 4 rev. Washington, American Psychiatric Association, 2000.
22 Daigre C, Ramos-Quiroga JA, Valero S, Bosch R, Roncero C, Gonzalvo B, Nogueira M, Casa M: Adult ADHD Self-Report Scale (ASRS-v1.1) symptom checklist in patients with substance use disorders. Actas Esp Psiquiatr 2009;37:299-305.

23 Lecrubier Y, Sheehan D, Weiller E, et al: The Mini International Neuropsychiatric Interview (MINI), a short diagnostic structured interview: reliability and validity according to the CIDI. Eur Psychiatry 1997;12:224-231.

24 Whiteside SP, Lynam DR, Miller JD, Reynolds SK: Validation of the UPPS Impulsive Behaviour Scale: a four-model of impulsivity. Eur J Pers 2005; 19:559-574.

25 Van der Linden M, d'Acremont M, Zermatten A, Jermann F, Laroi F, Willems S, Juillerat A, Bechara A: A French adaptation of the UPPS Impulsive Behavior Scale: confirmatory factor analysis in a sample of undergraduate students. Eur J Psychol Assess 2006;22: $38-42$.

26 Expertise-Collective: Jeux de hasard et d'argent. Contextes et addictions. Paris, Les éditions INSERM, 2008.

27 APA: Diagnostic and Statistical Manual of Mental Disorders, ed 4. Washington, American Psychiatric Association, 1994.

28 Breen RB, Zuckerman M: 'Chasing' in gambling behavior: personality and cognitive determinants. Pers Individ Dif 1999;27:10971111.

29 Boutin C: Le jeu: chance ou stratégie? Choisir librement la place du jeu dans votre vie. Montréal, Les Editions de l'Homme, 2010.

30 Weiss G, Hechtman L, Milroy T, Perlman T: Psychiatric status of hyperactives as adults: a controlled prospective 15-year follow-up of 63 hyperactive children. J Am Acad Child Psychiatry 1985;24:211-220.

31 Rasmussen P, Gillberg C: Natural outcome of ADHD with developmental coordination disorder at age 22 years: a controlled, longitudinal, community-based study. J Am Acad Child Adolesc Psychiatry 2000;39:14241431.

32 Barkley RA: Major life activity and health outcomes associated with attention-deficit/ hyperactivity disorder. J Clin Psychiatry 2002;63(suppl 12):10-15.

33 Ladouceur R: Perceptions among pathological and nonpathological gamblers. Addict Behav 2004;29:555-565.

34 Van Holst RJ, van den Brink W, Veltman DJ, Goudriaan AE: Why gamblers fail to win: a review of cognitive and neuroimaging findings in pathological gambling. Neurosci Biobehav Rev 2010;34:87-107.

-35 Cardinal RN, Winstanley CA, Robbins TW, Everitt BJ: Limbic corticostriatal systems and delayed reinforcement. Ann N Y Acad Sci 2004;1021:33-50.
36 DeVito EE, Blackwell AD, Clark L, Kent L, Dezsery AM, Turner DC, Aitken MR, Sahakian BJ: Methylphenidate improves response inhibition but not reflection impulsivity in children with attention deficit hyperactivity disorder (ADHD). Psychopharmacology (Berl) 2009;202:531-539.

37 Lawrence AJ, Luty J, Bogdan NA, Sahakian BJ, Clark L: Impulsivity and response inhibition in alcohol dependence and problem gambling. Psychopharmacology (Berl) 2009; 207:163-172.

- 38 Kertzman S, Vainder M, Vishne T, Aizer A, Kotler M, Dannon PN: Speed-accuracy trade-off in decision-making performance among pathological gamblers. Eur Addict Res 2010;16:23-30.

- 39 Lawrence AJ, Luty J, Bogdan NA, Sahakian BJ, Clark L: Problem gamblers share deficits in impulsive decision-making with alcoholdependent individuals. Addiction 2009;104: 1006-1015.

40 Klassen LJ, Katzman MA, Chokka P: Adult ADHD and its comorbidities, with a focus on bipolar disorder. J Affect Disord 2009;124: $1-8$

-41 Fischer AG, Bau CH, Grevet EH, Salgado CA, Victor MM, Kalil KL, Sousa NO, Garcia CR, Belmonte-de-Abreu P: The role of comorbid major depressive disorder in the clinical presentation of adult ADHD. J Psychiatr Res 2007;41:991-996.

42 Petry NM: Pathological Gambling. Etiology, Comorbidity, and Treatment. Washington, American Psychological Association, 2005.

43 Lesieur HR, Rosenthal RJ: Pathological gambling: a review of the literature. J Gambl Stud 1991;7:5-39.

-44 Bland RC, Newman SC, Orn H, Stebelsky G: Epidemiology of pathological gambling in Edmonton. Can J Psychiatry 1993;38:108112.

45 Cunningham-Williams RM, Cottler LB, Compton WM, Spitznagel EL: Taking chances: problem gamblers and mental health disorders: results from the Saint Louis Epidemiologic Catchment Area Study. Am J Public Health 1998;88:1093-1096.

-46 Hollander E, Buchalter AJ, DeCaria CM: Pathological gambling. Psychiatr Clin North Am 2000;23:629-642.

-47 Kruedelbach N, Walker HI, Chapman HA, Haro G, Mateu C, Leal C: Comorbidity on disorders with loss of impulse-control: pathological gambling, addictions and personality disorders. Actas Esp Psiquiatr 2006;34: 76-82.

48 Grall-Bronnec M, Bouju G, Guillou-Landreat $M$, Vénisse J: Evaluation socio-démographique, clinique et du parcours de jeu d'un échantillon de joueurs pathologiques français. Encéphale 2011 (in press).

49 Hallowell EM, Ratey JJ: Driven to Distraction: Recognizing and Coping with Attention Deficit Disorder from Childhood through Adulthood. New York, Pantheon, 1994. 
50 Blaszczynski A, Steel Z, McConaghy N: Impulsivity in pathological gambling: the antisocial impulsivist. Addiction 1997;92:75-87.

-51 Blaszczynski A, Nower L: A pathways model of problem and pathological gambling. Addiction 2002;97:487-499.

52 Billieux J, Gay P, Rochat L, Van der Linden M: The role of urgency and its underlying psychological mechanisms in problematic behaviours. Behav Res Ther 2010;48:10851096.

-53 Cyders MA, Smith GT: Mood-based rash action and its components: positive and negative urgency. Pers Individ Dif 2007;43:839850 .
54 Cyders MA, Smith GT: Emotion-based dispositions to rash action: positive and negative urgency. Psychol Bull 2008;134:807828.

55 Sullivan S, McCormick R, Lamont M, Penfold A: Problem gambling: patients affected by their own or another's gambling may approve of help from general practitioners. $\mathrm{NZ}$ Med J 2007;120:U2605.

56 Kessler RC, Green JG, Adler LA, Barkley RA, Chatterji S, Faraone SV, Finkelman M, Greenhill LL, Gruber MJ, Jewell M, Russo LJ, Sampson NA, Van Brunt DL: Structure and diagnosis of adult attention-deficit/hyperactivity disorder: analysis of expanded symptom criteria from the Adult ADHD Clinical Diagnostic Scale. Arch Gen Psychiatry 2010; 67:1168-1178.
57 Kooij JJS: Diagnostic interview for ADHD in adults 2.0 (DIVA 2.0); in Adult ADHD. Diagnostic Assessment and Treatment. Amsterdam, Pearson Assessment \& Information BV, 2010.

58 Nazar BP, Pinna CM, Coutinho G, Segenreich D, Duchesne M, Appolinario JC, Mattos P: Review of literature of attention-deficit/hyperactivity disorder with comorbid eating disorders. Rev Bras Psiquiatr 2008;30: 384-389.

59 Huizink AC, van Lier PA, Crijnen AA: Attention deficit hyperactivity disorder symptoms mediate early-onset smoking. Eur Addict Res 2009;15:1-9. 